\title{
The Top 5 Habits/Tips of a Highly Successful Emergency Physician
}

Kerryann B. Broderick, BSN, MD

\section{This article is adapted from a presentation given by Dr Broderick at the November 2017 American College of Emergency Physicians' (ACEP) Scientific Assembly in Washington, DC.}

Define It, Engage, Listen, Organize, and Closure. There, You Have It!

When I was asked to give this lecture at the 2017 American College of Emergency Physicians' (ACEP) Scientific Assembly, I literally snorted and looked over my shoulder. What? Moi give this lecture? Am I a successful emergency physician (EP)? Well, of course I am as the first emergency medicine (EM) residency-trained female professor at the University of Colorado, chair of the meetings subcommittee for the ACEP Educational Committee, and director on the American Board of Emergency Medicine.

What I have learned is that the first step to being successful is to define your personal barriers and self-defeating behaviors, and to identify and define your personal self-defeating behaviors-eg, perfectionism, procrastination, self-doubt?

My own personal self-defeating behavior is most certainly "imposter syndrome," which is very common among professionals. I first heard about imposter syndrome on my very first day of medical school, and this behavior still follows me today. I have written some short blurbs on this topic because I want others to know they are not alone. Highly successful people have this syndrome, and it can be very debilitating. What is imposter syndrome? According to Sandberg, "Despite being high achievers, even experts in their fields, women can't seem to shake the sense that it is only a matter of time until they are found out for who they really are- impostors with limited skills or abilities." ${ }^{1}$ Valerie Young, an internationally recognized expert on the subject, categorized imposter syndrome into five subgroups or habits: (1) the perfectionist; (2) the superwoman/man; (3) the natural genius; (4) the rugged individualist; and (5) the expert. In her book, The Secret Thoughts of Successful Women: Why Capable People Suffer From the Imposter Syndrome and How to Thrive in Spite of It, Young builds on decades of research studying fraudulent feelings among high achievers. ${ }^{2}$

\section{Identify Your Self-Defeating}

\section{Behaviors and Write Them Down}

Regarding the top five subgroups/habits proposed by Young unfortunately, there is no evidence-based literature on imposter syndrome. Most information consists of anecdotal reports from highly successful

Dr Broderick is a professor of emergency medicine, Denver Health Medical Center, Colorado, and University of Colorado at Denver. She also serves on the board of directors of the American Board of Emergency Medicine.

Author's Disclosure Statement: The author reports no actual or potential conflict of interest in relation to this article.

DOI: $10.12788 /$ emed.2018.0080 
people. When you read about successful habits from such individuals, they include such things as: efficiency; bring your Agame; embrace communication; personal wellness; and most importantly, growth mentality. ${ }^{3}$ You have most likely heard phrases such as, "Don't touch a piece of paper more than once." The "touch it once" philosophy maybe is efficient, but I'm not sure about it being a successful habit. ${ }^{4}$ The following is my list of the top five principles that I have used to guide my career.

\section{Define}

What is success to you? Are you thinking about your whole career, or just a successful shift or a successful triathlon? Do you want to win the triathlon or just finish it? Or, do you want to be a department chair? Define and set your goal(s), and make sure to reach and stretch yourself to the best of your abilities to attain your goal. To achieve your goal, you must force yourself out of your comfort zone. If you do not reach for something, chances are it is not going to drop in your lap.

When I attended my very first ACEP Scientific Assembly as a newly minted EM residency-trained EP, I thought the lectures were a bit too basic and needed to be at a higher level of knowledge. I decided I really wanted to be a part of that process. I defined my personal challenge as improving the ACEP educational content level, and I set my goal as getting on that committee. Your goal may be quite different-eg, maybe you wish to become the medical director of an ED, a residency program director, or an officer on your hospital's medical staff. Regardless of your goal, the first step is to decide and define what it is that you desire.

\section{Engage}

After you have defined and set your goal, the first steps to attaining it are to get started on the road you've chosen by showing up at relevant meetings, events; being present, engaging, and demonstrating curiosity. Maybe you will have an interesting journey!
I can't stress enough how important it is to just show up. Sometimes, you will find that you start in one direction and get pushed in another. One of the first steps I took to getting on the ACEP education committee was to ask other ACEP members and colleagues how to do so. Most told me that the education committee was a very highly regarded one and that perhaps I should start by getting on any ACEP committee-or even better, start with a section. A respected friend in the "know" suggested that I choose an ACEP committee/section of which I had high interest, and to just show up to one of the meetings. I have found this advice to be true for most of life, whether it's your hospital medical staff, local medical society, or state specialty society, or another professional organization-just show up.

\section{Listen}

When you do show up and attend a meeting or event, sit and listen to what others have to say, and when a task comes up with which you think you could be of assistance, step up and volunteer to help. When you are involved in a project or task, or are just listening, always keep an open mind-maybe your agenda is not exactly the same as other members of the organization/committee, but you will learn and gain important experience by being open to the thoughts and opinions of others.

When you step up and offer your assistance, you should make sure you volunteer for something that interests you. In general, to do a good job, the subject matter needs to be of interest to you, and the greater the interest, the more likely you are to be successful at completing the task. It also helps to make sure what you volunteer to do is attainable and realistic.

\section{Organize/Action}

After you've volunteered and committed yourself to a project, always be a productive member of the group. Do what you say you are going to do, and do it on time. These two simple things, completing your 
assignment/fulfilling your commitment and doing so on time, will set you apart from the pack. Do not be surprised when the reward for such an accomplishment is a request for you to do more, or take on leadership responsibilities.

Regarding my own personal journey, after I found out who served on the education committee. I started to set down some of the groundwork of networking, showing interest in the committee, and letting committee members know that I was very interested in their group and capable of helping in attaining their goals. Five years after taking these first steps to become involved in the group, I was appointed to serve on the meeting subcommittee of the ACEP education committee. This is the group that sets the curriculum and speakers for the Annual ACEP Scientific Assembly. I had made it! Then, after 8 years on the committee, I was appointed chair and worked hard to bring the meeting to Denver, Colorado, my home town. I pushed hard to reduce the length of many of the 50-minute lectures to $25 \mathrm{~min}$ utes, and also added some "rapid-fire" lectures to the curriculum.

\section{Failures}

On the path to attaining your goals, you will often encounter failure. It is important to keep in mind that if you never fail, then you probably are not reaching high or far enough. For example, I once wanted my institution to be more integrated at the affiliated University's campus. I had defined this as my goal. To reach it, when the annual election for the medical school faculty senate came along, I had as many of my faculty colleagues vote for me as secretary, the lowest faculty position available. To my shock, I got elected! The problem was, as the secretary, I was supposed to be present at all of the monthly meetings and actually take notes. Not only did I not know who any of the individuals speaking at these meetings were, but I could only make approximately $50 \%$ of the meetings due to scheduling conflicts and other commitments. It is my own shame for not doing my homework and learning the roles and responsibilities of the secretarial position. I had the definition of success as a vague one: I engaged but did not really have an attainable goal. After 3 months, I had to go to the dean and admit I had made a mistake and was not capable of performing the duty of secretary. Although, the dean understood and thanked me for my honesty, this was a humbling experience for me and one that also reflected poorly on my department.

However, we are all human and we do make mistakes. By acknowledging our mistakes and shortcomings, reflecting on why they happened, and learning how to handle and do things differently in the future is all part of the journey to success.

\section{Closure}

Did I find all of the time and work I put in over the years to be where I am now worth it to me personally? Was I successful? Yes on both counts! It was one long journey. In addition to the long-term journey, I also choose short ones. For example, I want a successful shift, which I now define as sitting down at least $50 \%$ of the time when taking a patient's history. I also want to be engaged with my patients. Remember, the key to being a successful EP is to set goals, whether they are long-term, short-term, major, or minor. So, reach, define, engage, listen, organize, and attain closure. Expect and be ready for some failures-these are steps on the path to success.

\section{References}

1. Sandberg S. Lean In: Women, Work, and the Will to Lead. New York, NY: Alfred A Knopf; 2013.

2. Young V. The Secret Thoughts of Successful Women: Why Capable People Suffer from the Impostor Syndrome and How to Thrive in Spite of It. 1st ed. New York, NY: Crown Business; 2011.

3. Silverman M. Step it up: 5 habits of successful EPs. Emergency Physicians Monthly Web site. http:// epmonthly.com/article/step-it-up-5-habits-of-successful-eps/. Published December 31, 2014. Accessed January 3, 2018.

4. Sexton Z. The "touch it once" principle that will skyrocket your personal efficiency. Asian Efficiency Web site. http://www.asianefficiency.com/mindsets/ touch-it-once-productivity-principle/. Accessed February 18, 2018. 